\section{Perioperative Cardiac Arrests}

\author{
JURAJ SPRUNG • RANDALL P. FLICK・STEPHEN J. GLEICH • \\ TOBY N. WEINGARTEN
}

JURAJ SPRUNG $(\bowtie) \cdot$ RANDALL P. FLICK・ STEPHEN J. GLEICH • TOBY N. WEINGARTEN Department of Anesthesiology College of Medicine Mayo Clinic 200 First Street SW, Rochester MN 55905, USA

Phone: (507) 255-3298

Fax: (507) 255-6463

E-mail: sprung.juraj@mayo.edu

\begin{abstract}
Perioperative cardiac arrests represent the most serious complication of anesthesia and surgery. It is believed that the incidence and mortality of cardiac arrest has declined, however, a more recent review questioned whether these rates have changed over the last 5 decades. It is difficult to compare the reports from different epochs, because medical practice has advanced, surgical acuity increased, and patients in extremes of age undergo surgery today. In the present article we review the information regarding the incidence of perioperative cardiac arrests and predictors of survival covering the period since the first comprehensive report by Beecher and Todd in 1954. We focus on our publications that report perioperative cardiac arrest at Mayo Clinic for adult noncardiac surgery, during regional anesthesia, and arrests in our pediatric surgical practice.
\end{abstract}

Key words: anesthesia, cardiac arrest, mortality

\section{Introduction}

In 1954, the first comprehensive study of anesthesia-related cardiac arrest and mortality in the United States was reported. (1) Numerous studies subsequently examined perioperative cardiac arrest, (2-17) but the incidence rate varied with the study period, the definition of the perioperative period, $(4,5,7-$ $9,11,12,18)$ and whether anesthesia directly caused cardiac arrest $(5,12)$ or was only a contributing factor. $(7,12)$ The incidence of cardiac arrest and mortality also varied with the type of surgery included in these studies; some examined all types of surgery, $(15,17,18)$ whereas others excluded cardiac surgical procedures.(13)

\section{Incidence of Perioperative Cardiac Arrest}

In the past several decades, the reported incidence of perioperative cardiac arrest has ranged between 4.6 and 19.7 per
10,000 anesthetics. $(7,12,13,15,16,18)$ We reported the frequency and outcome of perioperative cardiac arrest of 518,294 patients undergoing noncardiac surgery between 1990 and 2000 at the Mayo Clinic Rochester, Minnesota. (19) The perioperative period was defined as the time from the induction of anesthesia to dismissal from the anesthesia personnel care. The overall frequency of cardiac arrest was 4.3 per 10,000 anesthetics. The cardiac arrest occurred more frequently with general anesthesia $(5.5$ per 10,000$)$ than regional anesthesia (1.5 per 10,000) or monitored anesthesia care $(0.7$ per 10,000). Others have also observed higher rates of cardiac arrests with general anesthesia, but this may reflect that many high-risk surgical procedures are preferentially performed under general anesthesia. (20)

It is generally considered that the incidence of cardiac arrest during neuraxial anesthesia is lower than during general anesthesia. This was also a finding of our study. (19) A comprehensive sur- vey from France reported 2.7 cardiac arrests per 10,000 spinal anesthetics, (21) which was lower than the rate determined in an earlier study by the same authors (6.4 per 10,000). (22) More recently, Kopp et al. (23) evaluated the frequency of cardiac arrest during neuraxial anesthesia between 1983 and 2002 at Mayo Clinic. The overall frequency was 1.8 per 10,000 patients, with more arrests in patients receiving spinal anesthesia than epidural anesthesia (2.9 and 0.9 per 10,000, respectively).

At the Mayo Clinic, (19) the incidence of perioperative cardiac arrest decreased from 7.8 per 10,000 (1990-1992) to 3.2 per 10,000 (1998-2000). Such trends should be interpreted with caution because factors such as comorbid conditions of the patients and surgical acuity may change over time. Nevertheless, like many other medical centers, data from our practice suggest that recently treated patients were older and had more serious co-morbidities than patients treated in the earlier period. If 
this is true, the decrease in the frequency of perioperative cardiac arrest may imply a marked improvement in patient care over this period. Olsson and Hallen (13) also reported a declining incidence of cardiac arrest over time (1967-1984). However, a recent review questioned whether these rates had changed over the past 5 decades. $(7,13)$

\section{Cardiac Arrests Attributable to Anesthesia}

In our study of the anesthetic experience at the Mayo Clinic (19) only 24 cardiac arrests were attributable to anesthesia management. These arrests were classified into 2 categories, medication-related arrests (54.2\%) and airwayor ventilation-related arrests (45.8\%). The single largest etiologic category was cardiac arrest associated with the use of neuromuscular blocking agents (37.5\%) at emergence from anesthesia or in recovery room. This contrasts with findings of other studies of anesthesiarelated arrests, (10-13) which showed that although medication-related events were relatively common, events specifically involving neuromuscular blocking agents were infrequent. We cannot explain this difference, but practice-specific factors may be important determinants of cardiac arrests in our institution. Kopp et al. (23) studied 26 patients that had a cardiac arrest during neuraxial anesthesia; for 14 patients (54\%), the anesthetic agent contributed directly to the arrest (high sympathectomy or respiratory depression after sedative administration). The 12 other patients (46\%) had arrest associated with a specific surgical event (cementing of joint components, spermatic cord manipulation, and rupture of amniotic membranes).

In our study the majority of anesthesiarelated cardiac arrests were associated with asystole. (19) While in general hospital population asystole represents a terminal electrocardographic event with extremely poor outcome, (24) the asystolic presentation of cardiac arrest attributable to anesthetic causes had high survival rate (79.2\%). The reason for this is that anesthesia-related cardi- ac arrests were presumed to be caused by excessive parasympathetic tone (stretch of peritoneum, administration of anticholinesterase inhibitors without atropine or glycopyrollate, hypoxemia etc.), and these causes were more prone to reversal.

Although the rate of cardiac arrests due to anesthesia-related factors may have decreased over the past several decades, comparisons among studies are complicated by different surgical populations, definitions of cardiac arrest, and definitions of "anesthesiarelated" causes. (7) Keenan and Boyan $(5,6)$ described a decrease in the frequency of cardiac arrests associated with anesthesia, from 2.1 (1969-1978) to 1.0 per 10,000 anesthetics (19791988). A report from France showed 1.1 anesthesia-related cardiac arrests per 10,000 anesthetics.(25) Newland et al. (12) determined that the rate of anesthesia-related cardiac arrests for all surgical procedures was 2.1 per 10,000 anesthetics. When analysis was limited to arrests "definitely attributable to anesthesia," the rate was 0.69 per 10,000 anesthetics. At the Mayo Clinic, (19) the incidence of arrest primarily attributable to anesthesia was 0.5 per 10,000 anesthetics, which represented $10.8 \%$ of cardiac arrests that occurred perioperatively, a finding similar to the $10.4 \%$ reported by Newland et al. (12) The incidence of perioperative cardiac arrests directly attributable to anesthesia in pediatric patients undergoing anesthesia at the Mayo Clinic (26) was 0.65 per 10,000 anesthetics. Therefore, the incidence of anesthesia related cardiac arrest is comparable between adult and pediatric population.

\section{Factors Associated With Survival after Perioperative Cardiac Arrest}

At the Mayo Clinic, (19) in-hospital survival after perioperative cardiac arrest was $34.5 \%$; this is higher than the average survival rate after cardiac arrest for a general inpatient population (23\%). (24) Our findings are similar to those reported by Girardi and Barie (38\% survival), (27) who studied patients undergoing noncardiothoracic surgery between 1986 and 1994. The overall mortality rate after perioperative cardiac arrest, which is determined by the frequency of arrest and survival, has been reported to be between 2.4 (13) and 3.5 (15) per 10,000 anesthetics; both findings are similar to our reported value (2.8 per 10,000).

In previous studies, higher American Society of Anesthesiologists (ASA) Physical Status scores and urgency of surgical procedures were predictors of a high incidence of cardiac arrest and poor outcome. $(8,9,11,12,25,28)$ Our study of the Mayo Clinic experience (19) was not designed to calculate the frequency of arrest according to ASA Physical Status scores. However, even in our study higher ASA Physical Status scores was associated with an increased frequency of arrest. In addition, patients with higher ASA Physical Status scores had a higher mortality rate (20\% vs 46\%).

Morita et al. (29) found a high incidence of perioperative cardiac arrest and mortality for children younger than 1 month (incidence, 54.2 per 10,000; mortality, 43.0 per 10,000 ), but for other age groups, the incidence was between 2.6 and 11.0 per 10,000 anesthetics and mortality was between 1.7 and 6.6 per 10,000 anesthetics. Morray et al. (11) reviewed cardiac arrests from the Pediatric Perioperative Cardiac Arrest Registry and determined that age younger than 1 year was a predictor of poor outcome. This was confirmed in our study of pediatric arrests at the Mayo Clinic. (26) We found that incidence of cardiac arrest were highest among neonates undergoing cardiac procedures (incidence: 435 per 10,000). Incidence of cardiac arrests of all pediatric patients undergoing noncardiac procedures was 2.9 per 10,000 , and the incidence during cardiac procedures was 127 per 10,000. Therefore, in general, and looking across all pediatric ages (0-18 years), incidence of cardiac arrest in children is comparable or even lowering than in adults.

Extremes of age may give significant impact on survival after cardiac arrest. 
Table 1. Univariate Predictors of Hospital Survival after Perioperative Cardiac Arrest. From Sprung et al. (used with permission) (19)

\begin{tabular}{ll}
\hline Univariate Predictors of Cardiac Arrest & P \\
\hline ASA PS score $(\leq 3$ vs. $\geq 4)$ & 0.001 \\
\hline End-stage organ failure & 0.020 \\
\hline Diabetes mellitus & 0.030 \\
\hline Type of surgery* & 0.010 \\
\hline Emergency surgery & 0.001 \\
\hline Duration of surgery ${ }^{\dagger}$ & 0.030 \\
\hline Presence of protracted intraoperative hypotension & 0.001 \\
\hline Probable cause of arrest ${ }^{*}$ & 0.001 \\
\hline Time of arrest ${ }^{\dagger}$ & 0.001 \\
\hline Primary electrocardiographic rhythm & 0.020 \\
\hline
\end{tabular}

ASA PS, American Society of Anesthesiology Physical Status.

${ }^{*}$ General, orthopedic, neurologic, urologic vs. vascular, thoracic, trauma vs. transplantation; ${ }^{\dagger}$ In one hour increments; ${ }^{*}$ Bleeding vs. cardiac vs. all other causes; $\dagger^{\dagger} 07: 00$ to 20:00 Monday through Friday vs. 20:01 to 06:59 weekdays and Weekend. ${ }^{\S}$ Asystole vs. ventricular fibrillation vs. pulseless electrical activity.

Marx et al. (9) found poor outcomes after cardiac arrest in infants and elderly patients. Olsson and Hallen (13) found that the incidence of perioperative cardiac arrest for patients older than 80 years was 12.4 per 10,000 anesthetics, more than 4 times higher than that of the 30- to 39-year age group (2.6 per 10,000). In the Mayo Clinic experience (26) mortality was extremely high in neonates undergoing cardiac procedures, 389 per 10,000.

At Mayo Clinic survival was affected by the cause of arrest (table 1 and 2). (19) Only $10.3 \%$ of patients with hemorrhagic cardiac arrest survived to hospital dismissal, (19) a rate consistent with that of previous studies. $(17,27)$ The protracted hypotension before arrest was also a significant predictor of mortality (table 2) with survival rate of only $17.7 \%$.

Patients who had cardiac arrest during regular working hours (between 07:00 and 20:00, Monday through Friday) had better survival (tables 1 and 2). (19) Only $11.3 \%$ of patients whose arrests occurred during nonregular working hours (nights and weekends [Friday
20:01 through Monday 06:59]) survived to hospital dismissal. Newland et al. (12) determined that cardiac arrest occurred more frequently during "evening-night" hours. In our earlier study of outcome after in-hospital resuscitation that occurred outside of the perioperative period we found lower survival during night hours. (24) The lower rates were attributable to a disproportionately high incidence of nonwitnessed cardiac arrests at night, especially involving patients in unmonitored hospital beds, which resulted in delayed resuscitation. (24) In contrast, all our perioperative cardiac arrests were witnessed. (19) Therefore, if having a witnessed arrest was an independent predictor of survival, no difference in outcome should have been observed between patients with cardiac arrest during regular vs. nonregular working hours. However, patients who had perioperative cardiac arrest during regular working hours had 4.4-fold better survival. We speculate that patients with cardiac arrest during regular working hours may benefit from a more comprehensive response. Specifically, the response at our institution during regular working hours is characterized by the involvement of numerous anesthesia personnel. In addition, the response team has immediate access to resources that may not be available or may be delayed during nights or weekends.

The only comorbid condition associated with in-hospital mortality in our multivariate analysis was diabetes mellitus (tables 1 and 2). (19) The endorgan dysfunction associated with this condition may explain our finding, but it is interesting to note that the presence of other comorbid conditions such as cardiovascular and cerebrovascular diseases were not associated with worse survival after cardiac arrest. Only patients with end-stage organ failure had a lower survival rate (table 1). (19)

\section{Anesthesia-Related Mortality}

In our study, (19) in-hospital mortality caused by cardiac arrest attributable to anesthesia was approximately 1 per 100,000 anesthetics; this rate was similar to prior reports. $(8,30)$ Lagasse (7) challenged the assump- 
Table 2. Multivariate Characteristics Associated with Survival Following Perioperative Cardiac Arrest. From Sprung et al. (used with permission) (19)

\begin{tabular}{|c|c|c|c|}
\hline Characteristics & OR & $95 \% \mathrm{Cl}$ & $P$ \\
\hline \multicolumn{4}{|l|}{ Probable cause of arrest } \\
\hline Bleeding & 1.0 & -- & \multirow{3}{*}{0.001} \\
\hline Cardiac & 4.8 & $1.7-13.2$ & \\
\hline All other causes & 7.8 & $2.5-24.2$ & \\
\hline \multicolumn{4}{|l|}{ Time of arrest } \\
\hline \multicolumn{4}{|l|}{ Standard working } \\
\hline hours $^{\dagger}$ & 4.4 & $1.5-12.8$ & 0.006 \\
\hline Nonstandard working & 1.0 & -- & \\
\hline \multicolumn{4}{|l|}{ hours } \\
\hline \multicolumn{4}{|l|}{ Protracted hypotension } \\
\hline No & 1.0 & -- & $<0.001$ \\
\hline Yes & 0.3 & $0.1-0.6$ & \\
\hline \multicolumn{4}{|l|}{ Diabetes mellitus } \\
\hline No & 1.0 & -- & 0.008 \\
\hline Yes & 0.2 & $0.1-0.7$ & \\
\hline
\end{tabular}

$\mathrm{Cl}$, confidence interval; OR, odds ratio. ${ }^{\dagger}$ 07:00 to 20:00, Monday through Friday.

tion that anesthesia-related mortality has decreased over recent decades. Indeed, the 2 most recent studies of anesthesia-attributable mortality found somewhat higher rates $(0.55$ per 10,000 within 24 hours); (12) 0.75 and 0.79 per 10,000 within 48 hours, (7) but direct comparisons to our study should be made with caution. For example, patients undergoing cardiac surgery were included in another report, (12) but were not included in our study. We found that the outcome of patients with cardiac arrest attributable prima- rily to anesthesia was better than that of all other disease-related causes of cardiac arrest; the in-hospital survival was $79.2 \%$. (19) In contrast, Newland et al. (12) reported $80 \%$ mortality after anesthesia-attributable cardiac arrest.

\section{Conclusion}

From 1990 through 2000, the overall frequency of perioperative cardiac arrest in patients undergoing noncardiac surgery at the Mayo Clinic was 4.3 per 10,000 anesthetics. The annual incidence of cardiac arrest decreased over this period, but survival after arrest did not change significantly. The overall incidence of cardiac arrest attributable primarily to anesthesia was 0.5 per 10,000 anesthetics. Death after arrests attributable to anesthesia occurred in approximately 1 of 100,000 anesthetics. The disparity in survival among patients with arrests during regular and nonregular working hours may indicate that al least some factors leading to death after cardiac arrest may be preventable. This assumption needs to be validated in future studies.

* Portions of this chapter were previously published in Sprung et al. (19).

Used with permission.

\section{REFERENCES}

1. Beecher H, Todd DP. A study of the deaths associated with anesthesia and surgery. Ann Surg 1954;140:2-34.

2. Cohen MM, Duncan PG, Pope WD, Wolkenstein C. A survey of 112,000 anesthetics at one teaching hospital (1975-83). Can Anaesth Soc J 1986;33:22-31.

3. Harrison GG. Anesthetic contributory death-its incidence and causes. II. Causes. S Afr Med J 1968;42:544-9.

4. Harrison GG. Anesthetic-associated mortality. S Afr Med J 1974;48:550-4.

5. Keenan RL, Boyan CP. Cardiac arrest due to anesthesia. A study of incidence and causes. JAMA 1985;253:2373-7. 
6. Keenan RL, Boyan CP. Decreasing frequency of anesthetic cardiac arrests. J Clin Anesth 1991;3:354-7.

7. Lagasse RS. Anesthesia safety: model or myth? A review of the published literature and analysis of current original data. Anesthesiology 2002;97:1609-17.

8. Lunn JN, Devlin HB. Lessons from the confidential enquiry into perioperative deaths in three NHS regions. Lancet 1987;2:1384-6.

9. Marx GF, Mateo CV, Orkin LR. Computer analysis of postanesthetic deaths. Anesthesiology 1973;39:54-8.

10. Morgan CA, Webb RK, Cockings J, Williamson JA. The Australian Incident Monitoring Study. Cardiac arrest-an analysis of 2000 incident reports. Anaesth Intensive Care 1993;21:626-37.

11. Morray JP, Geiduschek JM, Ramamoorthy C, Haberkern CM, Hackel A, Caplan RA, et al. Anesthesia-related cardiac arrest in children: initial findings of the Pediatric Perioperative Cardiac Arrest (POCA) Registry. Anesthesiology 2000;93:6-14.

12. Newland MC, Ellis SJ, Lydiatt CA, Peters KR, Tinker JH, Romberger DJ, et al. Anesthetic-related cardiac arrest and its mortality: a report covering 72,959 anesthetics over 10 years from a US teaching hospital. Anesthesiology 2002;97:108-15.

13. Olsson GL, Hallen B. Cardiac arrest during anaesthesia. A computer-aided study in 250,543 anesthetics. Acta Anaesthesiol Scand 1988;32:653-64.

14. Pollard JB. Cardiac arrest during spinal anesthesia: common mechanisms and strategies for prevention. Anesth Analg 2001;92:252-6.

15. Pottecher T, Tiret L, Desmonts JM, Hatton F, Bilaine J, Otteni JC. Cardiac arrest related to anaesthesia: a prospective survey in France (1978-1982). Eur J Anaesthesiol 1984;1:305-18.

16. Tiret L, Desmonts JM, Hatton F, Vourc'h G. Complications associated with anaesthesia-a prospective survey in France. Can Anaesth Soc J 1986;33:336-44

17. Wu KH, Rau RH, Lin CF, Chan YL. Cardiac arrest during anesthesia in a teaching hospital. A 4 years survey. Int Surg 1997;82:254-6.

18. Minuck M. Cardiac arrest in the operating room-Part I (1965-1974). Canad Anaesth Soc J 1976;23:357-65.

19. Sprung J, Warner ME, Contreras MG, Schroeder DR, Beighley CM, Wilson GA, et al. Predictors of survival following cardiac arrest in patients undergoing noncardiac surgery: a study of 518,294 patients at a tertiary referral center. Anesthesiology 2003;99:259-69.

20. Aubas S, Biboulet P, Daures JP, du Cailar J. Incidence and etiology of cardiac arrest occurring during the peroperative period and in the recovery room. Apropos of 102,468 anesthesia cases. Ann Fr Anesth Reanim 1991;10:436-42.

21. Auroy Y, Benhamou D, Bargues L, Ecoffey C, Falissard B, Mercier FJ, et al. Major complications of regional anesthesia in France: The SOS Regional Anesthesia Hotline Service. Anesthesiology 2002;97:1274-80.

22. Auroy Y, Narchi P, Messiah A, Litt L, Rouvier B, Samii K. Serious complications related to regional anesthesia: results of a prospective survey in France. Anesthesiology 1997;87:479-86.

23. Kopp SL, Horlocker TT, Warner ME, Hebl JR, Vachon CA, Schroeder DR, et al. Cardiac arrest during neuraxial anesthesia: frequency and predisposing factors associated with survival. Anesth Analg 2005;100:855-65, table of contents.

24. Dumot JA, Burval DJ, Sprung J, Waters JH, Mraovic B, Karafa MT, et al. Outcome of adult cardiopulmonary resuscitations at a tertiary referral center including results of "limited" resuscitations. Arch Intern Med 2001;161:1751-8.

25. Biboulet P, Aubas P, Dubourdieu J, Rubenovitch J, Capdevila X, d'Athis F. Fatal and non fatal cardiac arrests related to anesthesia. Can J Anaesth 2001;48:326-32.

26. Flick RP, Sprung J, Harrison TE, Gleich SJ, Schroeder DR, Hanson AC, et al. Perioperative cardiac arrests in children between 1988 and 2005 at a tertiary referral center: a study of 92,881 patients. Anesthesiology 2007;106:226-37.

27. Girardi LN, Barie PS. Improved survival after intraoperative cardiac arrest in noncardiac surgical patients. Arch Surg 1995;130:15-8; discussion 9

28. Vacanti CJ, VanHouten RJ, Hill RC. A statistical analysis of the relationship of physical status to postoperative mortality in 68,388 cases. Anesth Analg 1970;49:564-6.

29. Morita K, Kawashima Y, Irita K, Iwao Y, Seo N, Tsuzaki K. Perioperative mortality and morbidity in 1999 with a special reference to age in 466 certified training hospitals of Japanese Society of Anesthesiologists-report of Committee on Operating Room Safety of Japanese Society of Anesthesiologists. Masui 2001;50:909-21.

30. Arbous MS, Grobbee DE, van Kleef JW, de Lange JJ, Spoormans HH, Touw P, et al. Mortality associated with anaesthesia: a qualitative analysis to identify risk factors. Anaesthesia 2001;56:1141-53. 